\section{The Scintillation of Stars}

IN a recent communication in Nature $^{1}$, Dr. A. H. R. Goldie has suggested that the scintillation of stars may be associated with waves at an interface between two currents of air which have a difference of tempera. ture of the order of $5-7^{\circ} \mathrm{F}$. "Such waves," he writes, "should not uncommonly have an amplitude of the order of up to $500-1,000 \mathrm{ft}$. at the interface, wave-length up to 10 miles or more, speed anything up to $\mathbf{4 0} \mathrm{ft}$. per sec., but probably usually Iower."

It does not seem likely that these waves are the cause of scintillation, for the following reasons. If these waves travel at usually not more than $40 \mathrm{ft}$. per sec. and have a wave-length of 10 miles, then three wave crests will pass a given point in one hour. Now stars twinkle at different periodicities, and in the case of Sirius each cycle has a duration of roughly 1 sec. and other stars are not very different. If this cycle is caused by air waves of ten miles wave-length, their rate of travel would have to be about one thousand times faster than that suggested by Dr. Goldie. Alternatively, if the speed he has suggested is correct, then the wave-length would have to be correspondingly shorter, say about $50 \mathrm{ft}$.

Apart, however, from the fact that the waves described by Dr. Goldie do not appear to have either the correct speed or the correct wave-length to fit in with the cycle of star scintillation, I have shown in previous letters that even if there were waves which did fit in with the cycle, they still would not produce the phenomena associated with scintillation. It wovld be expected that the waves would produce $(a)$ clearly marked side shifts at right-angles to the long axis of the waves, and $(b)$ spectra, owing to dispersion of light at the interface between the two air currents. But neither of these phenomena is to be found. What we do see when we look at stars are changes in light intensity and changes in colour, from pink through white to a pale blue-green. But neither the one nor the other can be adequately explained on the basis of air waves.

Vision Research Unit,

\section{H. HARTRIDGE}

Medical Research Council,

Institute of Ophthalmology, Judd Street, London, W.C.1.

${ }^{1}$ Nature, 165, 1019 (1950).

\section{Marching in Locust Hoppers of the Solitary Phase}

Locust species exist in two phases differing in colour, anatomy and behaviour with intermediate forms between the two extromes ${ }^{1,2}$. The nymphs (hoppers) of the gregarious phase are black and orange in colour; they congregate and wander or march in bands. Hoppers of the solitary phase are green or brown; they live in isolation and do not march. In the laboratory, the two phases can be produced by erowding or isolating the individuals during rearing.

Some field records mention green hoppers in gregarious bands; but it is generally assumed that marching is characteristic of the gregarious phase only. Kennedy ${ }^{3}$ first suggested, and Volkonsky ${ }^{4}$ put forward a definite hypothesis, that hoppers of the solitary phase also possess the necessary mechanisms for marching, the difference between the two phases being only quantitative.
It is now possible to obtain marching in cages, and I have compared the marching behaviour of fourth instar hoppers of the two phases of Locusta migratoria migratorioides (R. \& F.). Gregarious hoppers had gregarious parents, and solitary hoppers, solitary parents. The results confirm that marehing is a behaviour pattern not of the gregarious phase only, but of the locust species as a whole. There is, how. ever, a clear quantitative difference between the two phases, solitary hoppers marching for less of the time, and at lower speeds, than hoppers of the gregarious phase.

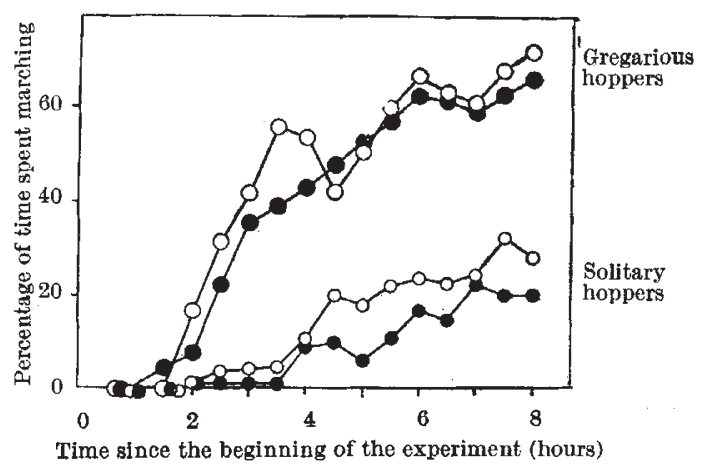

In the first group of experiments, eighteen hoppers of the same phase were put together in a cage, and the percentage of time spent marching recorded for marked individuals. The accompanying graph gives the results for two experiments on each phase, and shows that solitary hoppers march, but for less of the time than gregarious hoppers. During the last three hours of these experiments, the speeds of hoppers while marching were recorded. The averages of twenty results for each phase are shown in Table 1 . The difference is significant ; hoppers of the solitary phase march more slowly than those of the gregarious phase.

Table 1. Marching Sphed (cm. per sec.)

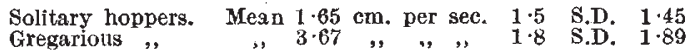

Difference between the means, 8.78 times the standard error of the difference and thus signiflicant.

In the second group of experiments, single marked solitary and gregarious hoppers were dropped into a cage of marching gregarious hoppers, and their activities noted for a specified length of time. The avorage percentage of time spent in marching for each hopper was calculated, and the results analysed statistically (Table 2). These results show that solitary hoppers are capable of joining a marching stream, but there is again a quantitative difference between the two phases.

Table 2. Percentage of TTME Spent Marohing Solitary hoppers. Mean $26 \cdot 1 \% \quad 3.8 \%$ S.D. $16 \cdot 1 \quad$ No. of cases 18 Gregarious ," " $49 \cdot 2 \% \quad 2 \cdot 6 \%$ S.D. $15 \cdot 0 \quad$ ", ", 33 Difference between the means, 5.05 times the standard error of the difference and thus signiflcant.

This work is being carried out with the aid of a grant from the Anti-Locust Research Centre, London.

Department of Zoology, PegGy E. ELIIS

University College, London. March 27.

${ }^{1}$ Uvarov, B P., Bull. Ent. Res., 12, 135 (1921).

- Faure, J. C., Bull. Ent. Res., 23, 293 (1932).

3 Kennedy J S Trans. Roy. Ent Soc, Lond, 89, 385 (1939):

Volkonsky, M., Arch. Inst. Pasteur Algerie, 20, 237 (1942). 